\title{
Transversus Abdominis Plane Block in Colorectal Surgery: A Meta-Analysis
}

\author{
Dmitriy Viderman $^{1 *}$, Mina Aubakirova $^{1}$ and Yerkin G. Abdildin ${ }^{2}$ \\ ${ }^{1}$ Department of Biomedical Sciences, Nazarbayev University School of Medicine (NUSOM), Nur-Sultan, Kazakhstan, \\ ${ }^{2}$ Department of Mechanical and Aerospace Engineering, School of Engineering and Digital Sciences, Nazarbayev University, \\ Nur-Sultan, Kazakhstan
}

Acute postoperative pain is one of the most common concerns during the early postoperative period in colorectal surgery. Opioids still represent the cornerstone of postoperative pain management, yet they often result in significant side effects such as nausea and/or vomiting, sedation, urinary retention, delayed recovery of colonic motility, respiratory depression, and postoperative ileus. Transversus abdominis plane (TAP) block has been widely used for postoperative analgesia in various abdominal surgeries. The primary aim of this meta-analysis was to compare the postoperative opioid requirements of patients in the TAP block group and the control group (placebo). The secondary aims included evaluation of the efficacy of TAP blocks in postoperative pain management, the measurement of time to first request for opioids, the measurement of length of hospital stay (LOS), and the documentation of postoperative nausea and/or vomiting. We searched for articles reporting the results of randomized controlled trials (RCTs) on the application of TAP block in colorectal surgery published before September 2021. Eight RCTs involving 615 patients were included in the meta-analysis. Seven articles reported the results of TAP blocks in laparoscopic surgery and eight in both laparoscopic and open surgery. The need for opioids and the intensity of pain at rest within $24 \mathrm{~h}$ after laparoscopic and combined (laparoscopic and open) surgeries were significantly lower in the TAP block group compared with the "no block" group. The intensity of pain during coughing within 24 hours after laparoscopic surgery was significantly lower in the TAP block groups compared to the groups without block. There were no statistically significant differences between the TAP block and "no block" groups in overall (over the entire hospital stay) postoperative opioid consumption and length of hospital stay after laparoscopic surgery, as well as in postoperative nausea and vomiting after laparoscopic and combined surgeries.

\footnotetext{
Keywords: transversus abdominis plane (TAP) block, colorectal surgery, postoperative pain management, regional anesthesia, opioid consumption
}

\section{BACKGROUND}

Colorectal surgery is one of the most frequently performed operations in abdominal surgery (1). Acute postoperative pain is one of the most common negative effects in the early postoperative period in colorectal surgery (2). Opioids still represent the cornerstone of postoperative pain management; however, they often result in significant side effects such as nausea and/or vomiting, sedation, urinary retention, delayed recovery of colonic motility, respiratory depression, and 
postoperative ileus $(3,4)$. Postoperative epidural analgesia had played an important role in postoperative pain management after colorectal surgery (5); however, it poses the risk of procedure-related complications (6). One of the options for the adequate management of postoperative pain in such surgeries is to use regional anesthetic techniques. The transversus abdominis plane (TAP) block has been widely used for postoperative analgesia in various abdominal surgeries. The TAP block is achieved through a direct blockade of the nerve afferent supplying the abdominal wall. TAP blocks target the ventral rami of intercostal nerves carrying pain fibers in the plane between the transversus abdominis and internal oblique muscles. Numerous studies have demonstrated that TAP blocks provide adequate analgesia and decrease postoperative opioid consumption after various operations including colorectal surgery (7), retropubic prostatectomy (8), cesarean delivery (9), abdominal hysterectomy (10), laparoscopic appendectomy, and incision hernia repair (11). The TAP block was introduced into clinical anesthesia to reduce postoperative pain and opioid consumption (12). However, meta-analyses of well-controlled studies focusing on TAP blocks in minimally invasive colorectal surgery are still lacking.

The main purpose of this meta-analysis was to compare the postoperative opioid requirements of patients with TAP blocks with patients within a control group (placebo). Secondary aims included the evaluation of the efficacy of TAP blocks in postoperative pain management, increase in time to first request for opioids, decrease in length of hospital stay (LoS), and decrease postoperative nausea and/or vomiting.

\section{METHODS}

\section{Protocol}

We designed a protocol of the current systematic review (SR) with the inclusion and exclusion criteria for suitable articles. The SR protocol and methods of analysis were approved by all authors. We considered only randomized controlled trials (RCTs) that compared the analgesic effects of TAP block in colorectal surgery.

We followed the "Preferred Reporting Items for Systematic Reviews and Meta-Analyses (PRISMA)" (13) to prepare this systematic review.

We followed the PICO criteria:

Population: 18 years and older undergoing colorectal surgery (both open and laparoscopic).

Intervention: Transversus abdominis plane block.

Comparator: Placebo (sham).

Outcomes:

Primary - to assess opioid consumption within the first $24 \mathrm{~h}$ after surgery:

a) In laparoscopic colorectal surgery only.

b) In both laparoscopic and open.

Secondary - to assess the pain intensity scores following surgery; time to first request for rescue opioids; side effects of opioids (e.g., nausea and/or vomiting, pruritis respiratory depression); local anesthetic systemic toxicity (LAST), mechanical injury by the needle:

a) In laparoscopic colorectal surgery only.

b) In both laparoscopic and open.

\section{Inclusion Criteria}

1) TAP block (both preoperative and postoperative) in acute pain management after colorectal surgery and standard noninterventional pain management methods assessed using the standard scales (VAS or NRS).

2) Randomized controlled trials (RCTs).

3) Age - 18 years old and older.

4) Colorectal surgery (both laparoscopic and open).

\section{Exclusion Criteria}

We excluded studies that were not RCTs, which are case reports or series, editorials, cadaver studies, retrospective studies, technical reports.

\section{Search Methods}

We performed a search for relevant articles in PubMed, Google Scholar, and the Cochrane Library published during the period from the inception of these databases to September 2021. The search included the following search terms or their combinations $\{[(($ "transversus abdominis plane block,") "transversus abdominis plane”] “TAP block,") “TAPB” $\}$ AND $\{[$ (“colorectal surgery”) "colon surgery"] OR "colon resection"\}.

\section{Data Extraction and Statistical Methods}

We calculated the sample mean and sample $S D$ from data presented in 1st quartile, median, 3rd quartile, and sample size using the methods developed by Luo et al. (14) for the sample mean and by Wan et al. (15) for sample SD. We converted postoperative opioid doses into intravenous morphine equivalents (mg) to standardize outcome measures (16-18).

To convert fentanyl used in the reported studies to the equivalent morphine dose we used the following multiplier: 0.01 . Doses reported in mcg were converted to mg dividing by 1,000 . Data analysis was conducted using the Review Manager software (RevMan, version 5.4.1). Statistical heterogeneity was estimated by the $\mathrm{I}^{2}$ statistic.

\section{Assessment of Methodological Quality}

The methodological quality of the RCTs was assessed independently by two reviewers using the Oxford quality scoring system [Jadad Scale (19)]. The quality of included studies was categorized within the range from $1(\min )$ to $5(\max )$ as low $(<3)$, acceptable (3), good (4), and excellent (5).

\section{RESULTS}

In this study, 92 articles were initially identified by the systematic search, in which 84 articles did not match the including criteria and were excluded (Figure 1). Among the remaining articles, 8 RCTs with 615 patients were included in the meta-analysis. Furthermore, 7 articles reported the results of TAP blocks in 


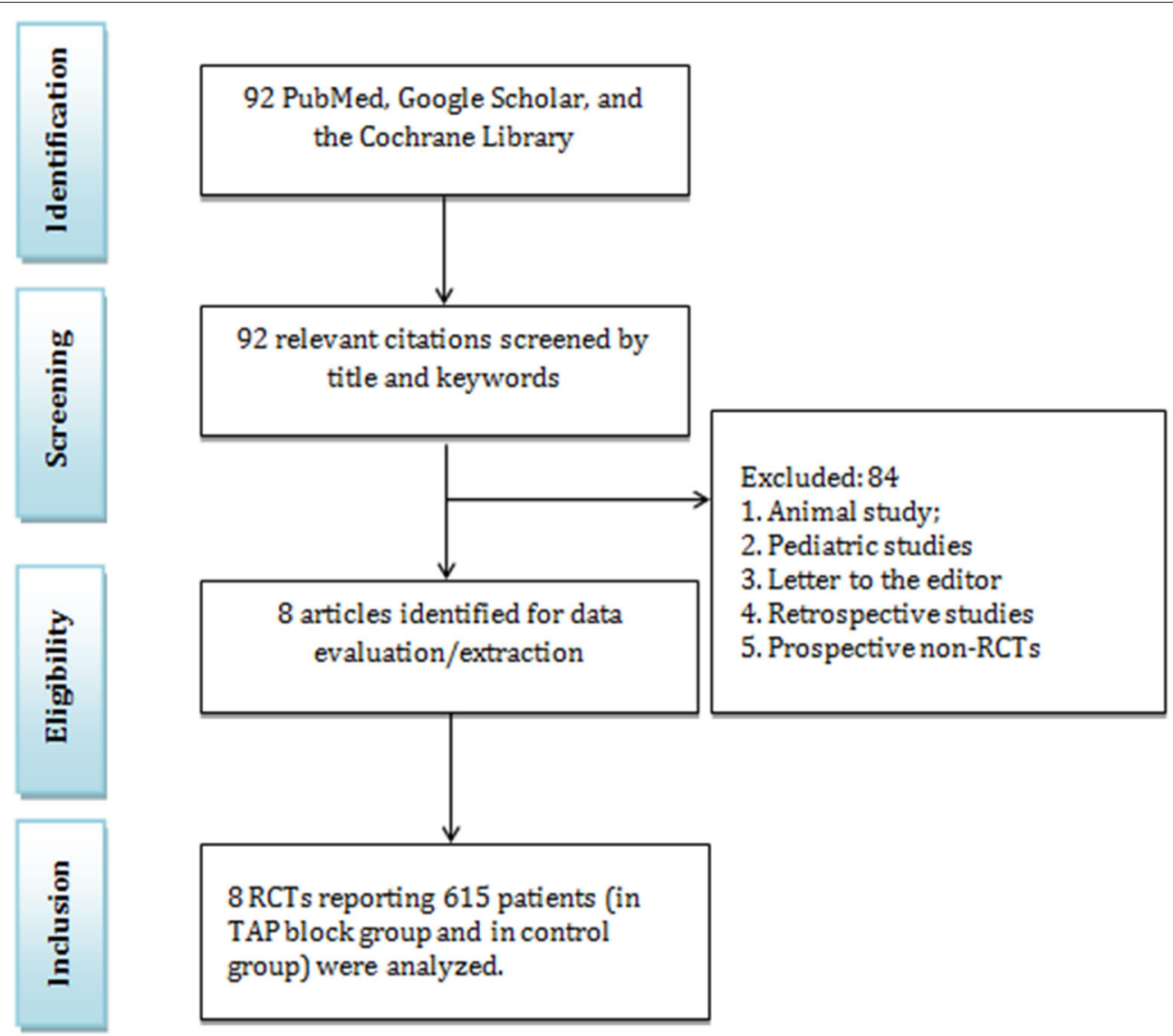

FIGURE 1 | PRISMA diagram.

laparoscopic surgery and eight in both laparoscopic and open surgery. We analyzed the data related to postoperative opioid consumption, the efficacy of TAP blocks in the reduction of pain intensity, time to first need for opioids, the rate of postoperative side effects and complications in the TAP block group and "no block" group (Table 1). These studies were conducted in Thailand, the UK, the USA, South Korea, India, and Australia. In addition to the TAP block, the following analgesics were used: paracetamol, ketorolac, fentanyl (as PCA), flurbiprofenaxetil, sufentanil IV, morphine, hydromorphone, and oxycodone. The patient demographic data are presented in Table 1. There were no significant differences in age, ASA classification, and comorbidities. The most common types of colorectal surgeries included right hemicolectomy, left hemicolectomy, anterior resection, ileocolic and sigmoid resection (Table 2).

\section{Volume, Dose, and Concentration of Local Anesthetics}

Three local anesthetics were used for TAP block (Table 1): ropivacaine (in 3 studies), bupivacaine (in 5 studies), and levobupivacaine (in 1 study). The authors reported using a concentration and dose of ropivacaine from $0.375 \%-2.5 \mathrm{mg} / \mathrm{kg}$ (in 2 studies) to $0.375 \%-3 \mathrm{mg} / \mathrm{kg}-20 \mathrm{ml}$ on each side (in 1 study). The concentration and dose of bupivacaine varied from
$0.2 \%$ (given as a $5 \mathrm{ml}$ bolus and continued as an infusion for $72 \mathrm{~h}$ ) to $0.5 \mathrm{~mL} / \mathrm{kg}$ of. $5 \%$ bupivacaine, maximum volume $-30 \mathrm{ml}$. Levobupivacaine was given as $40 \mathrm{~mL} 2 \mathrm{mg}$ / levobupivacaine (150 $\operatorname{mg} \max )$.

\section{Opioid Consumption Within $24 \mathrm{~h}$ After Surgery (in mg of Morphine)}

Three studies in our meta-analysis $(22,26,27)$ reported the total morphine consumption in $\mathrm{mg}$, and one (20) in fentanyl in mcg delivered via PCA which we converted into morphine consumption in $\mathrm{mg}$. Walter et al. (26) reported data for open surgery and laparoscopic colorectal surgery. They also reported the postoperative opioid consumption separately for laparoscopic colorectal surgery (LCS), so we used that data to keep consistency with other studies. Bharti et al. (27) conducted colorectal surgery via midline abdominal incision.

One study (25) reported the opioid consumption (morphine equivalent) in the postanesthesia care unit (PACU) and using the Defined Daily Dose (DDD), but since we consider values at $24 \mathrm{~h}$ after surgery, we could not include this study in our metaanalysis. Another study (23) reported the postoperative analgesic consumption in $\mathrm{mL}$ and it was not clear which opioid was used, so we were unable to include that study results in our analysis. 
TABLE 1 | Characteristics of studies included in the meta-analysis.

\begin{tabular}{|c|c|c|c|c|c|c|c|c|c|c|c|}
\hline $1^{\text {st }}$ author, citation & Country & $\begin{array}{l}\text { Study } \\
\text { design }\end{array}$ & Study goals & $\begin{array}{l}\text { Age (TAP/ } \\
\text { intervention } \\
2 / \text { Control, } \\
\text { mean } \pm \text { SD) }\end{array}$ & $\begin{array}{l}\mathrm{N} \text { of patients: } \\
\text { total (TAP/ } \\
\text { intervention } \\
\text { 2/Control) }\end{array}$ & Group & Surgery & $\begin{array}{l}\text { General } \\
\text { anesthesia }\end{array}$ & $\begin{array}{l}\text { ASA } \\
\text { status }\end{array}$ & $\begin{array}{l}\text { Local } \\
\text { anesthetics, } \\
\text { volume and } \\
\text { concentration, } \\
\text { adjuvants }\end{array}$ & $\begin{array}{l}\text { Postoperative } \\
\text { analgesia }\end{array}$ \\
\hline $\begin{array}{l}\text { Haruethaivijitchock } \\
\text { et al. (20) }\end{array}$ & Thailand & $\mathrm{RCT}$ & $\begin{array}{l}\text { Primary - } \\
\text { fentanyl consumption; } \\
\text { Secondary - pain } \\
\text { scores, recovery } \\
\text { outcome, } \\
\text { and complications }\end{array}$ & $\begin{array}{c}65.44 \pm 8.16 \\
/ 64.19 \pm 10.98\end{array}$ & $51(25 / 26)$ & $\begin{array}{l}\text { TAP: Modified } \\
\text { continuous TAP } \\
\text { C: Control }\end{array}$ & $\begin{array}{l}\text { Laparoscopic } \\
\text { colorectal surgery }\end{array}$ & Yes & $|-|||$ & $\begin{array}{l}\text { TAP: } 0.2 \% \\
\text { bupivacaine } 5 \mathrm{ml} \\
\text { bolus than } 72 \mathrm{~h} \\
\text { infusion } \\
\text { C: Normal saline }\end{array}$ & $\begin{array}{l}\text { Oral paracetamol + } \\
\text { IV-PCA: Fentanyl }\end{array}$ \\
\hline Xu et al. (21) & China & $\mathrm{RCT}$ & $\begin{array}{l}\text { Primary - hospital LOS } \\
\text { Secondary - } \\
\text { gastrointestinal motility, } \\
\text { pain scores, plasma } \\
\text { levels of cytokines }\end{array}$ & $\begin{array}{l}60.4 \pm 9.3 / \\
61.4 \pm 9.3 / \\
58.4 \pm 10.4\end{array}$ & $\begin{array}{l}165(55 / 55 / 55) \\
\text { Patients in TEA } \\
\text { group }(n=55) \\
\text { were not } \\
\text { included in } \\
\text { the meta- } \\
\text { analysis }\end{array}$ & $\begin{array}{l}\text { TAP: Single-shot } \\
\text { bilateral subcostal and } \\
\text { posterior TAP } \\
\text { TEA (was not included } \\
\text { in meta-analysis) }\end{array}$ & $\begin{array}{l}\text { Laparoscopic } \\
\text { colorectal cancer } \\
\text { surgery }\end{array}$ & Yes & $|-||| \mid$ & $\begin{array}{l}\text { TAP: } 2.5 \mathrm{mg} / \mathrm{kg} \\
0.375 \% \\
\text { ropivacaine }\end{array}$ & $\begin{array}{l}\text { Flurbiprofen, for } 48 \mathrm{~h} \\
\text { Rescue analgesia: } \\
\text { Sufentanil; TAP: } \\
\text { Infusion pump ropivacaine; } \\
\text { GA: IV-PCA } 1 \mu \mathrm{g} / \mathrm{ml} \\
\text { sufentanil, bolus } 2 \mathrm{~mL}\end{array}$ \\
\hline Damadi et al. (22) & USA & $\mathrm{RCT}$ & $\begin{array}{l}\text { Primary - total IV } \\
\text { narcotic consumption } \\
\text { Secondary - time to } \\
\text { ambulation, time to } \\
\text { bowel function, LOS }\end{array}$ & $\begin{array}{l}28.3 / \\
28.4 / \\
30.5\end{array}$ & $\begin{array}{l}123(41 / 51 / 31) \\
\text { Patients in ERP } \\
\text { group }(n=51) \\
\text { were not } \\
\text { included in } \\
\text { the meta- } \\
\text { analysis }\end{array}$ & $\begin{array}{l}\text { TAP: TAP under } \\
\text { laparoscopic } \\
\text { visualization } \\
\text { C: Control }\end{array}$ & $\begin{array}{l}\text { Elective } \\
\text { laparoscopic } \\
\text { colorectal } \\
\text { resection }\end{array}$ & $N G$ & $N G$ & $\begin{array}{l}\text { TAP: } 40 \text { cc of } \\
0.25 \% \\
\text { bupivacaine } \\
\text { C: } 40 \text { cc of } 0.9 \% \\
\text { normal saline }\end{array}$ & $\begin{array}{l}\text { Fentanyl, morphine, or } \\
\text { hydromorphone. Surgical } \\
\text { wards: Tylenol PO e } \\
\text { ibuprofen, + IV } \\
\text { hydromorphone or }\end{array}$ \\
\hline Oh et al. (23) & Korea & $\mathrm{RCT}$ & $\begin{array}{l}\text { Primary - pain score on } \\
\text { coughing on day } 1 \\
\text { Secondary - pain at } \\
\text { rest at all times and } \\
\text { pain at coughing on } \\
\text { days } 2,3\end{array}$ & $\begin{array}{l}\text { median: } \\
66 / 65\end{array}$ & $55(28 / 27)$ & $\begin{array}{l}\text { TAP: US-guided TAP } \\
\text { C: Control }\end{array}$ & $\begin{array}{l}\text { Laparoscopic } \\
\text { surgery for } \\
\text { colorectal cancer }\end{array}$ & Yes & $|-|||$ & $\begin{array}{l}\text { TAP: } 0.5 \mathrm{~mL} / \mathrm{kg} \\
0.25 \% \\
\text { bupivacaine } \\
\text { C: } 0.5 \mathrm{~mL} / \mathrm{kg} \\
\text { normal saline }\end{array}$ & $\begin{array}{l}\text { IV-PCA: Morphine } 0.5 \\
\mathrm{mg} / \mathrm{mL} \text { and fentanyl } 10 \\
\mu \mathrm{g} / \mathrm{mL}\end{array}$ \\
\hline Smith et al. (24) & Australia & $\mathrm{RCT}$ & $\begin{array}{l}\text { Primary - } \\
\text { analgesic consumption } \\
\text { Secondary - pain } \\
\text { scores, respiratory } \\
\text { function, PONV, } \\
\text { hospital LOS, } \\
\text { complications, } \\
\text { patient satisfaction }\end{array}$ & $\begin{array}{l}64.82 \pm 14.19 / \\
63.16 \pm 14.49\end{array}$ & $142(68 / 74)$ & $\begin{array}{l}\text { TAP: US-guided } \\
\text { bilateral TAP } \\
\text { C: Standard care }\end{array}$ & $\begin{array}{l}\text { Laparoscopic } \\
\text { colorectal } \\
\text { resectional surgery }\end{array}$ & $\begin{array}{l}\text { Yes } \\
y\end{array}$ & I-IV & $\begin{array}{l}\text { TAP: } 3 \mathrm{mg} / \mathrm{kg} \\
\text { ropivacaine } 40 \mathrm{~mL} \\
(20 \mathrm{~mL} \text { on each } \\
\text { side) } \\
\text { C: None }\end{array}$ & $\begin{array}{l}\text { Paracetamol; PCA: } \\
\text { Fentanyl } 20 \mu \mathrm{g} \text { bolus, }\end{array}$ \\
\hline Keller et al. (25) & USA & $\mathrm{RCT}$ & $\begin{array}{l}\text { Pain scores, opioid } \\
\text { use, PONV, short-term } \\
\text { outcomes }\end{array}$ & $\begin{array}{l}67.34 \pm 14.16 / \\
64.82 \pm 13.11\end{array}$ & $77(41 / 36)$ & $\begin{array}{l}\text { TAP: TAP under } \\
\text { laparoscopic } \\
\text { visualization } \\
\text { C: Control }\end{array}$ & $\begin{array}{l}\text { Elective } \\
\text { laparoscopic } \\
\text { colorectal surgery }\end{array}$ & $N G$ & I-IV & $\begin{array}{l}\text { TAP: } 0.5 \mathrm{ml} / \mathrm{kg} \text { of } \\
0.5 \% \text { bupiva- } \\
\text { caine, max } 30 \mathrm{~mL} \\
\text { C: } 0.5 \mathrm{ml} / \mathrm{kg} \text { of } \\
0.9 \% \text { normal } \\
\text { saline, max } 30 \mathrm{~mL}\end{array}$ & $\begin{array}{l}\text { PCA morphine } \\
\text { Nursing floor: } \\
\text { Gabapentin + Toradol; } \\
\text { Tylenol oral + oxycodone }\end{array}$ \\
\hline
\end{tabular}




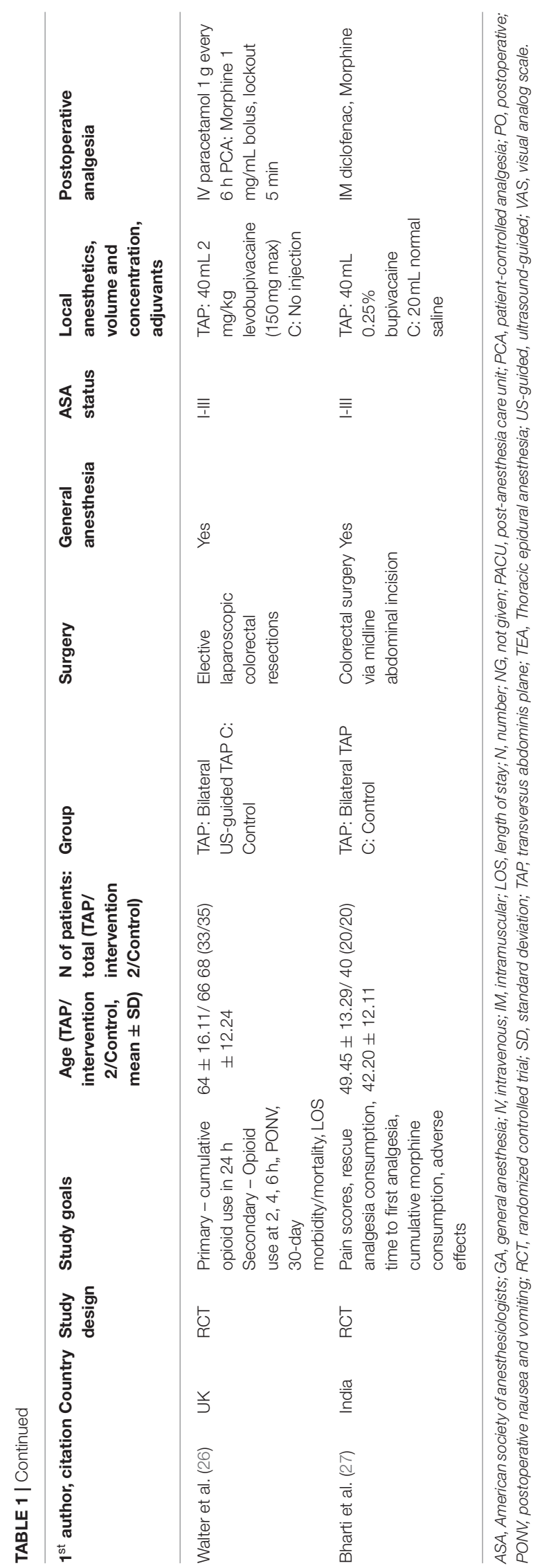

Therefore, only three studies provided data on postoperative opioid consumption for laparoscopic surgery. The opioid consumption within $24 \mathrm{~h}$ after surgery is presented in the forest plot (Figure 2). Although the overall effect favors TAP block over no block (control group), confidence intervals cross zero in two studies. Due to different types of opioids used in the studies, we constructed the model with the random effects analysis and the standardized mean difference for the effect measure; the standardized mean difference with $95 \% \mathrm{CI}$ is as follows: -0.48 $[-0.82,-0.14]$. Since the studies have similar sample sizes, the weights of the studies are approximately equal $(\sim 28-38 \%)$. The total number of patients in the TAP block groups is 97 , while in the control groups there are 87 patients. The value of $\mathrm{I}^{2}$ is equal to $23 \%$, the model shows heterogeneity, so we performed the sensitivity analysis by excluding one study at a time. The model is sensitive to the results of two studies $(20,26)$, in which case the model is indifferent between TAP block and no block.

Afterward, we included both laparoscopic and open surgeries, namely, colorectal surgery via midline abdominal incision like in Bharti et al. Walter et al. (26) presented data for open and laparoscopic surgeries, as well as laparoscopic only. The results slightly changed. The opioid consumption within $24 \mathrm{~h}$ after surgery is presented in the forest plot in Figure 3. The model still favors TAP block over no block (control group), the standardized mean difference with $95 \% \mathrm{CI}$ is now: -0.94 $[-1.65,-0.23]$. Since the studies have similar sample sizes, the weights of the studies are approximately equal $(\sim 22-27 \%)$. The total number of patients in the TAP block groups is now 119, while in the control groups there are 112 patients. The value of $\mathrm{I}^{2}$ is equal to $84 \%$, so the model shows high heterogeneity and this is significant since the $P$-value is equal to 0.0003 . Due to the high heterogeneity of the studies, we performed the sensitivity analysis by excluding one study at a time. The model is sensitive to the results of a study by Haruethaivijitchock et al. (20).

\section{Overall Postoperative Opioid Consumption (in mg of Morphine)}

Only three studies reported the overall postoperative opioid consumption, but one of them (20) did not provide complete data values, so we were unable to include them in this analysis. Smith et al. (24) reported data in terms of the sample mean and SEM, so we estimated the sample $S D$ as $\operatorname{SEM}{ }^{*} \operatorname{SQRT}(n)$, where $n$ is the sample size. This, however, makes the $S D$ considerably larger than in other studies, e.g., in Damadi et al. (22). As we can see, the overall effect does not favor TAP block over the no block alternative, but with a larger number of studies, we could have received clearer results (Figure 4).

\section{Pain Intensity in NRS/VAS Scores at Rest Recorded $24 \mathrm{~h}$ After Surgery}

The pain intensity measured in NRS/VAS scores at rest recorded $24 \mathrm{~h}$ after laparoscopic surgery is presented in the forest plot (Figure 5). The model includes four studies (20, 21, 23, 25). In this model, we used the standardized mean difference as 
TABLE 2 | Distribution of the types of colorectal surgeries.

\begin{tabular}{|c|c|c|c|c|c|}
\hline First author, year & Type of surgery & TAP block, $n$ & TAP block, $\%$ of 317 & Control, $n$ & Control, \% of 322 \\
\hline \multirow{4}{*}{$\begin{array}{l}\text { Haruethaivijitchock et al. } \\
\text { (20) }\end{array}$} & Right hemicolectomy & 10 & $3.2 \%$ & 11 & $3.4 \%$ \\
\hline & Anterior resection & 5 & $1.6 \%$ & 7 & $2.2 \%$ \\
\hline & Sigmoid resection & 0 & $0.0 \%$ & 2 & $0.6 \%$ \\
\hline & Subtotal colectomy & 3 & $0.9 \%$ & 12 & $3.7 \%$ \\
\hline & Left hemicolectomy & 10 & $3.2 \%$ & 8 & $2.5 \%$ \\
\hline & Anterior resection & 16 & $5.0 \%$ & 20 & $6.2 \%$ \\
\hline & Sigmoid resection & 11 & $3.5 \%$ & 11 & $3.4 \%$ \\
\hline \multirow[t]{3}{*}{ Damadi et al. (22) } & Anterior resection & 4 & $1.3 \%$ & 6 & $1.9 \%$ \\
\hline & Ileocolic/sigmoid resection (non-specified) & 30 & $9.5 \%$ & 25 & $7.8 \%$ \\
\hline & Abdominal perineal resection & 3 & $0.9 \%$ & 0 & $0.0 \%$ \\
\hline \multirow[t]{2}{*}{ Oh et al. (23) } & Colon (non-specified) & 11 & $3.5 \%$ & 18 & $5.6 \%$ \\
\hline & Rectum (non-specified) & 17 & $5.4 \%$ & 9 & $2.8 \%$ \\
\hline \multirow[t]{4}{*}{ Smith et al. (24) } & Right hemicolectomy & 29 & $9.1 \%$ & 34 & $10.6 \%$ \\
\hline & Left hemicolectomy & 3 & $0.9 \%$ & 5 & $1.6 \%$ \\
\hline & Anterior resection & 33 & $10.4 \%$ & 35 & $10.9 \%$ \\
\hline & Subtotal colectomy & 4 & $1.3 \%$ & 0 & $0.0 \%$ \\
\hline \multirow[t]{5}{*}{ Keller et al. (25) } & Resection rectopexy & 1 & $0.3 \%$ & 1 & $0.3 \%$ \\
\hline & Anterior resection & 3 & $0.9 \%$ & 8 & $2.5 \%$ \\
\hline & Ileocolic/sigmoid resection (non-specified) & 32 & $10.1 \%$ & 27 & $8.4 \%$ \\
\hline & Abdominal perineal resection & 1 & $0.3 \%$ & 1 & $0.3 \%$ \\
\hline & Total abdominal colectomy & 3 & $0.9 \%$ & 1 & $0.3 \%$ \\
\hline \multirow{13}{*}{$\begin{array}{l}\text { Types of operations } \\
\text { sorted by the number } \\
\text { of patients in } \\
\text { descending order }\end{array}$} & Anterior resection & 61 & $19.2 \%$ & 76 & $23.7 \%$ \\
\hline & Not mentioned & 20 & $6.3 \%$ & 20 & $6.2 \%$ \\
\hline & Left hemicolectomy & 20 & $6.3 \%$ & 17 & $5.3 \%$ \\
\hline & Left and rectal resection (non-specified) & 19 & $6.0 \%$ & 21 & $6.5 \%$ \\
\hline & Rectum (non-specified) & 17 & $5.4 \%$ & 9 & $2.8 \%$ \\
\hline & Colon (non-specified) & 11 & $3.5 \%$ & 18 & $5.6 \%$ \\
\hline & Sigmoid resection & 11 & $3.5 \%$ & 13 & $4.0 \%$ \\
\hline & Subtotal colectomy & 7 & $2.2 \%$ & 12 & $3.7 \%$ \\
\hline & Total abdominal colectomy & 5 & $1.6 \%$ & 1 & $0.3 \%$ \\
\hline & Abdominal perineal resection & 4 & $1.3 \%$ & 1 & $0.3 \%$ \\
\hline & Colostomy reversal & 2 & $0.6 \%$ & 0 & $0.0 \%$ \\
\hline & Total proctocolectomy & 1 & $0.3 \%$ & 1 & $0.3 \%$ \\
\hline & Resection rectopexy & 1 & $0.3 \%$ & 1 & $0.3 \%$ \\
\hline
\end{tabular}

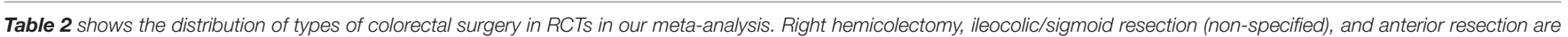
the three main types of surgery that were used together in 62.8 and $64.8 \%$ of patients in the TAP block and control groups, respectively.

a summary statistic because all studies measure the same outcome (pain intensity score), but measure it using different scales (NRS/VAS). In this analysis, there are 149 patients in the TAP groups and 145 patients in the control groups. Since the number of patients in each study is of the same order, the model assigns comparable weights for each study (from 19 to $33.1 \%)$.

This model shows that the patients tend to have less pain intensity after laparoscopic surgery when TAP block was applied compared to the patients in the control group, the standardized 


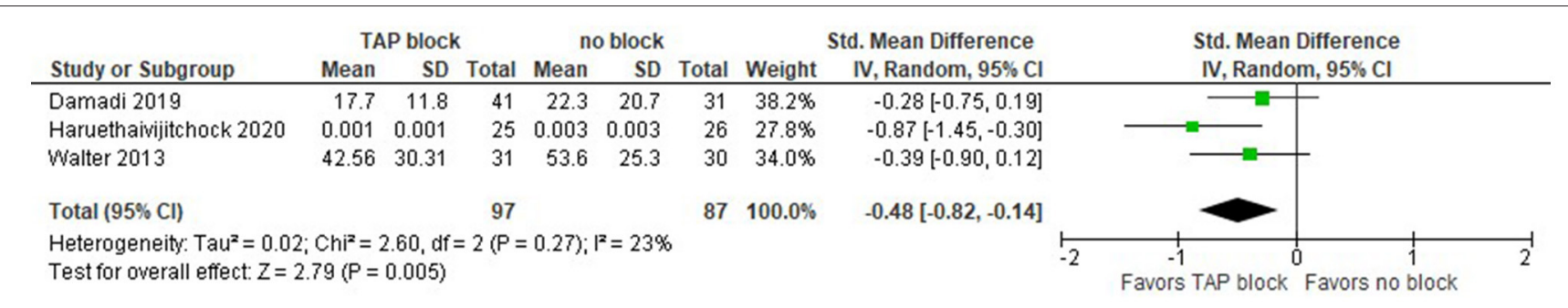

FIGURE 2 | Forest plot for total opioid consumption within $24 \mathrm{~h}$ after surgery in mg of morphine (only laparoscopic surgeries).

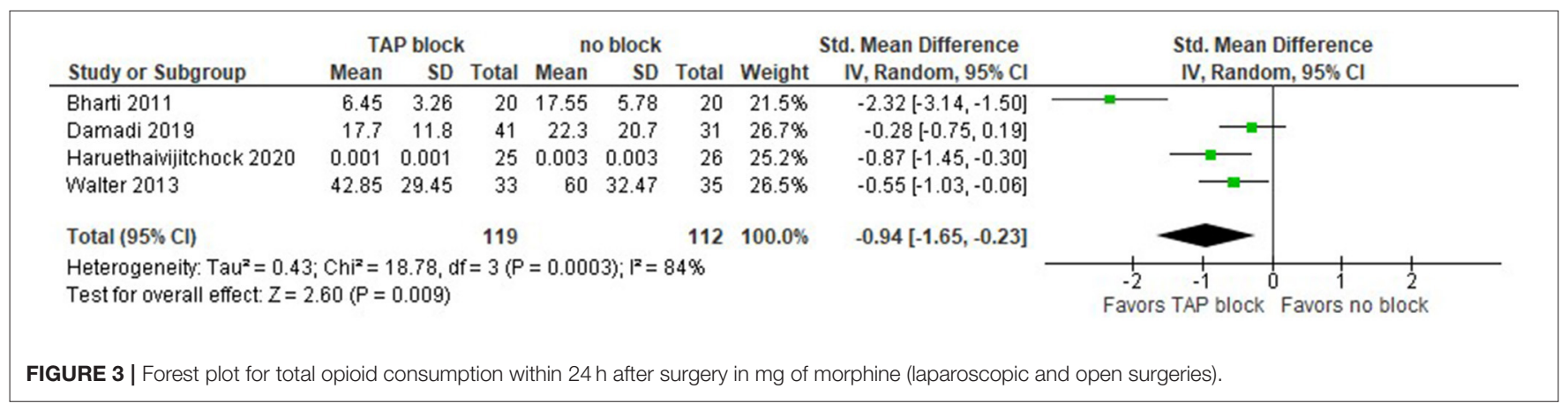

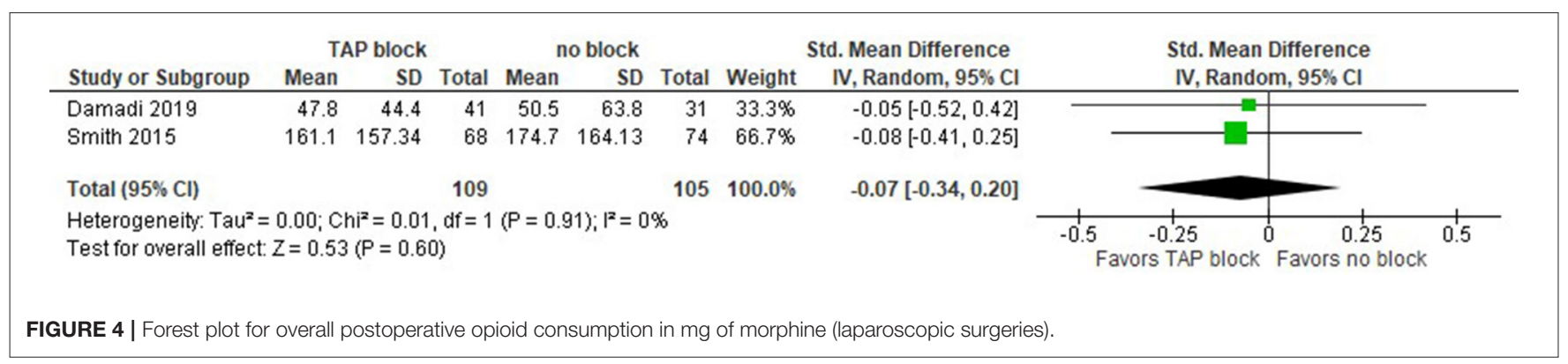

\begin{tabular}{|c|c|c|c|c|c|c|c|c|c|c|c|}
\hline \multirow[b]{2}{*}{ Study or Subgroup } & \multicolumn{3}{|c|}{ TAP } & \multicolumn{3}{|c|}{ Control } & \multicolumn{2}{|c|}{ Std. Mean Difference } & \multirow{2}{*}{\multicolumn{3}{|c|}{$\begin{array}{l}\text { Std. Mean Difference } \\
\text { IV, Random, } 95 \% \mathrm{Cl}\end{array}$}} \\
\hline & Mean & SD & Total & Mean & SD & Total & Weight & IV, Random, $95 \% \mathrm{Cl}$ & & & \\
\hline Haruethaivijitchock 2020 & 1.04 & 1.21 & 25 & 1.76 & 1.71 & 25 & $19.0 \%$ & $-0.48[-1.04,0.08]$ & & + & \\
\hline Keller 2014 & 2.6 & 2.09 & 41 & 3.46 & 1.92 & 38 & $26.9 \%$ & $-0.42[-0.87,0.02]$ & 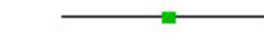 & & \\
\hline Oh 2016 & 4 & 1.6 & 28 & 3.9 & 1.7 & 27 & $21.0 \%$ & $0.06[-0.47,0.59]$ & & & \\
\hline$x u 2020$ & 1.7 & 0.55 & 55 & 2.1 & 0.74 & 55 & $33.1 \%$ & $-0.61[-0.99,-0.23]$ & $\longrightarrow$ & & \\
\hline Total $(95 \% \mathrm{Cl})$ & & & 149 & & & 145 & $100.0 \%$ & $-0.39[-0.67,-0.12]$ & & & \\
\hline \multicolumn{7}{|c|}{$\begin{array}{l}\text { Heterogeneity: } \mathrm{Tau}^{2}=0.02 ; \mathrm{Chi}^{2}=4.13, \mathrm{df}=3(P=0.25) ; \mathrm{I}^{2}=27 \% \\
\text { Test for overall effect: } Z=2.80(P=0.005)\end{array}$} & & & $\begin{array}{l}-0.5 \\
\text { Favors TAP }\end{array}$ & 0.5 & 1 \\
\hline
\end{tabular}

mean difference with $95 \% \mathrm{CI}$ is as follows: $-0.39[-0.67,-0.12]$. This result is not strong though, because the confidence intervals cross zero in three studies. The sensitivity analysis showed that the result is sensitive to the exclusion of one study at a time. In addition, Bharti et al. (27) found that "TAP group patients had significantly lower pain scores at rest," but they provided only a graphical representation of their result and we were unable to include their result in our meta-analysis. Considering 20 patients in both TAP and control groups in their study, their result would add additional points to the TAP block. 


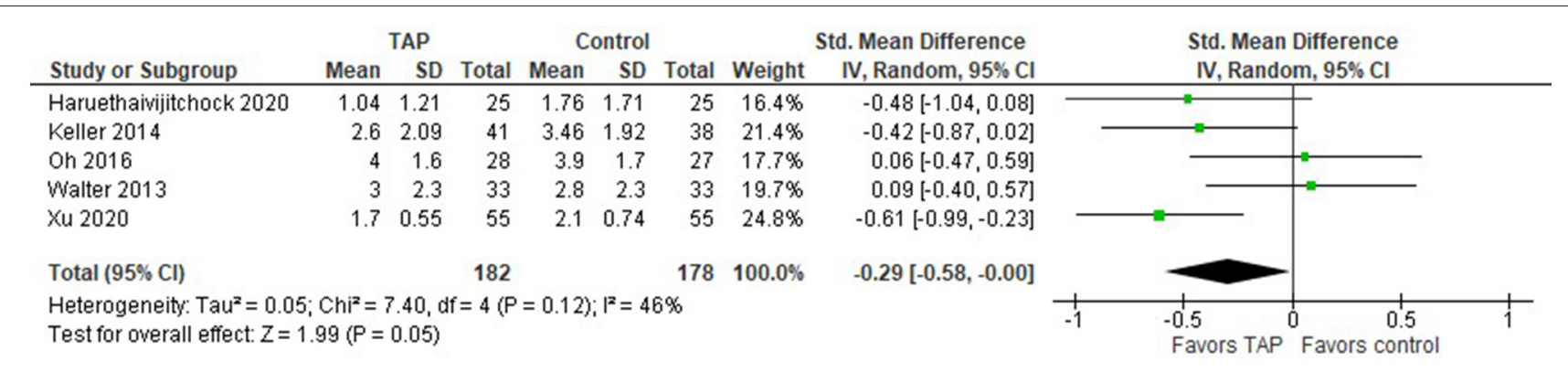

FIGURE 6 | Forest plot for the pain intensity score in NRSNAS at rest recorded $24 \mathrm{~h}$ after laparoscopic and open surgeries.

When both laparoscopic and open surgeries are considered, the model (Figure 6) still favors TAP block over the no block option, but the overall effect becomes closer to the no-difference point, the standardized mean difference with $95 \% \mathrm{CI}$ is as follows: $-0.29[-0.58,-0.00]$.

\section{Pain Intensity Score in NRS/VAS When Coughing at $24 \mathrm{~h}$ After Surgery}

Three studies in our analysis compared TAP block with no block management in terms of the pain intensity scores when patients are coughing. The forest plot in Figure 7 favors the TAP block when coughing at the time $24 \mathrm{~h}$ after the surgery. The model is not sensitive to the exclusion of any study, the summary effect does not change significantly. No heterogeneity was observed across studies.

\section{Length of Hospital Stay (Days)}

An interesting result is observed in terms of the length of hospital stay (LOS) after laparoscopic surgery. The meta-analysis shows no difference between TAP block and non-block options (Figure 8). In studies by Damadi et al. (22) and Keller et al. (25), the LOS was shorter in the control group than in the TAP block group, while in a study by Haruethaivijitchock et al. (20) there was no difference.

We should mention here that in the latter study, the data were presented as mean (5) and IQR (4.6), so we assumed that the authors meant that (4.6) are the $1^{\text {st }}$ and $3^{\text {rd }}$ quartiles. One study did not report the sample $S D$; we were unable to incorporate its result into the forest plot. In particular, Smith et al. (24) reported the sample mean (7.5 vs 6.3) and median (4 for both) of LOS for TAP block and control groups.

\section{Postoperative Side Effects (Nausea and Vomiting)}

Postoperative side effects (nausea and vomiting) from opioids in the TAP and control groups are depicted in the forest plot below for laparoscopic surgery (Figure 9). The summary effect of the model shows no difference between TAP block and non-block options (risk ratio with 95\% CI: $0.60[0.23,1.56]$ ), and the result is insensitive to the exclusion of any study.

We should mention that since Smith et al. (24) did not provide the overall number of patients in PONV, we used the values for PONV $24 \mathrm{~h}$ after surgery, which were the largest values in their reports among PONV values at 24,48 , and $72 \mathrm{~h}$. Xu et al. (21) reported the mean values of the PONV case, not the actual number of patients, but we assume that the sample mean could be a reasonable estimate for this analysis.

The model (Figure 10) shows no difference between TAP block and no block when we consider both laparoscopic and open surgeries (risk ratio with 95\% CI: 0.77 [0.33, 1.81]). This result is not sensitive to the exclusion of any study.

\section{Assessment of Methodological Quality (Jadad/Oxford Quality Scoring System)}

Further results showed that six out of eight studies were graded as excellent (5/5 points), one - as good ( $4 / 5$ points), and one as acceptable (3/5). The grading of the included studies is presented in Table 3.

\section{DISCUSSION}

This meta-analysis reports the evidence on the clinical position of the TAP block in pain management after laparoscopic colorectal surgery. TAP block was found to decrease the cumulative opioid requirement within $24 \mathrm{~h}$ after surgery in both groups: laparoscopic alone and combined (laparoscopic and open). However, the effect of TAP block in reducing opioid requirements was more pronounced in the combined group. It can be explained by a more extensive surgical incision in open colorectal surgery. Therefore, TAP block was more clinically useful in patients after open surgery, and compared to "no block", patients who received TAP block required much fewer opioids. Nevertheless, there was no statistically significant difference in overall opioid requirement after laparoscopic surgery. TAP block was superior to "no block" in reducing the pain intensity at rest and on coughing within $24 \mathrm{~h}$ after surgery in both groups: laparoscopic alone and combined (laparoscopic and open). There were no statically significant differences in length of hospital stay. There were no statistically significant differences between the TAB block and no block in the incidence of postoperative nausea and vomiting in both groups: laparoscopic alone and combined (laparoscopic and open).

Colorectal surgery is among the most frequently performed types of abdominal surgeries. Nowadays, there is a tendency toward shifting from open to laparoscopic surgeries. Minimally 


\begin{tabular}{|c|c|c|c|c|c|c|c|c|c|c|c|}
\hline \multirow[b]{2}{*}{ Study or Subgroup } & \multicolumn{3}{|c|}{ TAP } & \multicolumn{3}{|c|}{ Control } & \multicolumn{2}{|c|}{ Std. Mean Difference } & \multirow{2}{*}{\multicolumn{2}{|c|}{$\begin{array}{l}\text { Std. Mean Difference } \\
\text { IV, Random, } 95 \% \mathrm{Cl}\end{array}$}} & \\
\hline & Mean & SD & Total & Mean & SD & Total & Weight & IV, Random, $95 \% \mathrm{Cl}$ & & & \\
\hline Haruethaivijitchock 2020 & 3.44 & 0.98 & 25 & 4.24 & 1.71 & 25 & $23.3 \%$ & $-0.57[-1.13,0.00]$ & $\Longrightarrow-$ & & \\
\hline Oh 2016 & 5.6 & 1.8 & 28 & 6.1 & 1.6 & 27 & $26.4 \%$ & $-0.29[-0.82,0.24]$ & $\longrightarrow$ & - & \\
\hline$x u 2020$ & 4.2 & 1.29 & 55 & 5.1 & 1.29 & 55 & $50.3 \%$ & $-0.69[-1.08,-0.31]$ & - 는 & & \\
\hline Total $(95 \% \mathrm{Cl})$ & & & 108 & & & 107 & $100.0 \%$ & $-0.56[-0.83,-0.28]$ & & & \\
\hline \multicolumn{7}{|c|}{$\begin{array}{l}\text { Heterogeneity. } \operatorname{Tau}^{2}=0.00 ; \mathrm{Chi}^{2}=1.45, \mathrm{df}=2(P=0.48) ; I^{2}=0 \% \\
\text { Test for overall effect: } Z=3.99(P<0.0001)\end{array}$} & & $\stackrel{-2}{ }$ & $\begin{array}{l}-1 \\
\text { Favors TAP }\end{array}$ & $\begin{array}{cc}1 \\
0\end{array}$ & 2 \\
\hline
\end{tabular}

\begin{tabular}{|c|c|c|c|c|c|c|c|c|c|c|c|}
\hline \multirow[b]{2}{*}{ Study or Subgroup } & \multicolumn{3}{|c|}{ TAP block } & \multicolumn{3}{|c|}{ no block } & \multirow[b]{2}{*}{ Weight } & \multirow{2}{*}{$\begin{array}{l}\text { Mean Difference } \\
\text { IV, Random, } 95 \% \mathrm{CI}\end{array}$} & \multirow{2}{*}{\multicolumn{2}{|c|}{$\begin{array}{c}\text { Mean Difference } \\
\text { IV, Random, } 95 \% \mathrm{Cl}\end{array}$}} & \\
\hline & Mean & SD & Total & Mean & SD & Total & & & & & \\
\hline Damadi 2019 & 5.1 & 2.3 & 41 & 4.3 & 2.4 & 31 & $13.1 \%$ & $0.80[-0.30,1.90]$ & & & \\
\hline Haruethaivijitchock 2020 & 5 & 1.57 & 25 & 5 & 1.57 & 25 & $18.3 \%$ & $0.00[-0.87,0.87]$ & & & \\
\hline Keller 2014 & 3.15 & 2.03 & 41 & 2.87 & 1.58 & 38 & $20.5 \%$ & $0.28[-0.52,1.08]$ & & & \\
\hline Xu 2020 & 3 & 0.55 & 55 & 3.3 & 0.74 & 55 & $48.1 \%$ & $-0.30[-0.54,-0.06]$ & - 는 & & \\
\hline Total $(95 \% \mathrm{Cl})$ & & & 162 & & & 149 & $100.0 \%$ & $0.02[-0.44,0.47]$ & & & \\
\hline $\begin{array}{l}\text { Heterogeneity: Tau }=0.10 \\
\text { Test for overall effect: } Z=\end{array}$ & $\begin{array}{l}\mathrm{Chi}^{2}=5 \\
08(\mathrm{P}=\end{array}$ & $\begin{array}{l}\text {.41, df } \\
0.94)\end{array}$ & $f=3(P$ & $=0.14) ;$ & $1^{2}=45$ & & & -2 & $\begin{array}{lc} & -1 \\
& \text { Favors TAP block }\end{array}$ & $\begin{array}{c}1 \\
\text { Favors no block }\end{array}$ & $\frac{1}{2}$ \\
\hline
\end{tabular}

\begin{tabular}{|c|c|c|c|c|c|c|c|c|c|c|}
\hline Study or Subgroup & \multicolumn{2}{|c|}{ TAP block } & \multicolumn{2}{|c|}{ no block } & Weight & Risk Ratio & \multicolumn{4}{|c|}{$\begin{array}{c}\text { Risk Ratio } \\
\mathrm{M}-\mathrm{H}, \text { Random, } 95 \% \mathrm{Cl}\end{array}$} \\
\hline Haruethaiwijitchock 2020 & 1 & 25 & 9 & 25 & $12.1 \%$ & $0.11[0.02,0.81]$ & & $\because-$ & & \\
\hline Keller 2014 & 10 & 41 & 9 & 38 & $21.5 \%$ & $1.03[0.47,2.26]$ & & & - & \\
\hline Oh 2016 & 6 & 28 & 6 & 27 & $19.7 \%$ & $0.96[0.35,2.62]$ & & & & \\
\hline Smith 2015 & 62 & 68 & 57 & 74 & $24.9 \%$ & $1.18[1.02,1.37]$ & & & $=$ & \\
\hline Xu 2020 & 7 & 55 & 27 & 55 & $21.8 \%$ & $0.26[0.12,0.54]$ & & - & & \\
\hline Total $(95 \% \mathrm{CI})$ & & 217 & & 219 & $100.0 \%$ & $0.60[0.23,1.56]$ & & & & \\
\hline Total events & 86 & & 108 & & & & & & & \\
\hline $\begin{array}{l}\text { Heterogeneity: } \operatorname{Tau}^{2}=0.96 \\
\text { Test for overall effect: } Z=\end{array}$ & $\begin{array}{l}\mathrm{Chi}^{2}=36 \\
06(P=0 .\end{array}$ & $\begin{array}{l}69, \mathrm{df} \\
\text { 29) }\end{array}$ & $=4(P<0$ & 0.0000 & 1); $\left.\right|^{2}=89 \%$ & & 0.01 & $\begin{array}{c}0.1 \\
\text { Favors TAP block }\end{array}$ & $\begin{array}{c}10 \\
\text { Favors no block }\end{array}$ & 100 \\
\hline
\end{tabular}

\begin{tabular}{|c|c|c|c|c|c|c|c|c|c|c|}
\hline \multirow[b]{2}{*}{ Study or Subgroup } & \multicolumn{2}{|c|}{ TAP block } & \multicolumn{2}{|c|}{ no block } & \multirow[b]{2}{*}{ Weight } & \multirow{2}{*}{$\begin{array}{c}\text { Risk Ratio } \\
\text { M-H, Random, } 95 \% \mathrm{Cl} \\
\end{array}$} & \multirow{2}{*}{\multicolumn{4}{|c|}{$\begin{array}{c}\text { Risk Ratio } \\
\text { M-H, Random, } 95 \% \mathrm{Cl}\end{array}$}} \\
\hline & Events & Total & Events & Total & & & & & & \\
\hline Haruethaivijitchock 2020 & 1 & 25 & 9 & 25 & $10.2 \%$ & $0.11[0.02,0.81]$ & & $\because$ & & \\
\hline Keller 2014 & 10 & 41 & 9 & 38 & $19.4 \%$ & $1.03[0.47,2.26]$ & & & 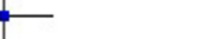 & \\
\hline Oh 2016 & 6 & 28 & 6 & 27 & $17.6 \%$ & $0.96[0.35,2.62]$ & & & & \\
\hline Smith 2015 & 62 & 68 & 57 & 74 & $23.1 \%$ & $1.18[1.02,1.37]$ & & & 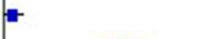 & \\
\hline Walter 2013 & 7 & 33 & 1 & 34 & $10.0 \%$ & $7.21[0.94,55.46]$ & & & & \\
\hline Xu 2020 & 7 & 55 & 27 & 55 & $19.7 \%$ & $0.26[0.12,0.54]$ & & & & \\
\hline Total $(95 \% \mathrm{Cl})$ & & 250 & & 253 & $100.0 \%$ & $0.77[0.33,1.81]$ & & & & \\
\hline Total events & 93 & & 109 & & & & & & & \\
\hline $\begin{array}{l}\text { Heterogeneity: } \operatorname{Tau}^{2}=0.8 \\
\text { Test for overall effect: } Z=\end{array}$ & $\begin{array}{l}\mathrm{Chi}^{2}=33 \\
59(\mathrm{P}=0\end{array}$ & $\begin{array}{l}3.93, \mathrm{df} \\
.55)\end{array}$ & $=5(P<$ & 0.00001 & 1); $\left.\right|^{2}=85$ & & 0.01 & $\begin{array}{c}0.1 \\
\text { Favors TAP block }\end{array}$ & $\begin{array}{c}10 \\
\text { Favors no block }\end{array}$ & 100 \\
\hline
\end{tabular}


TABLE 3 | Oxford quality scoring system (Jadad Scale).

\begin{tabular}{|c|c|c|c|c|c|c|}
\hline First author, year & $\begin{array}{l}\text { Was the study } \\
\text { described as } \\
\text { randomized? }\end{array}$ & $\begin{array}{l}\text { Was the method used } \\
\text { to generate the } \\
\text { sequence of } \\
\text { randomization } \\
\text { described and } \\
\text { appropriate? }\end{array}$ & $\begin{array}{c}\text { Was the study } \\
\text { described as double } \\
\text { blind? }\end{array}$ & $\begin{array}{l}\text { Was the method of } \\
\text { double blind } \\
\text { described and } \\
\text { appropriate? }\end{array}$ & $\begin{array}{l}\text { Was there a } \\
\text { description of } \\
\text { withdraw and } \\
\text { dropouts? }\end{array}$ & Total score \\
\hline $\begin{array}{l}\text { Haruethaivijitchock } \\
\text { et al. (20) }\end{array}$ & 1 & 1 & 1 & 1 & 1 & 5 \\
\hline Xu et al. (21) & 1 & 1 & 0 & 0 & 1 & 3 \\
\hline Damadi et al. (22) & 1 & 1 & 1 & 1 & 1 & 5 \\
\hline Oh et al. (23) & 1 & 1 & 1 & 1 & 1 & 5 \\
\hline Smith et al. (24) & 1 & 1 & 1 & 1 & 1 & 5 \\
\hline Keller et al. (25) & 1 & 1 & 1 & 1 & 1 & 5 \\
\hline Walter et al. (26) & 1 & 1 & 1 & 1 & 1 & 5 \\
\hline Bharti et al. (27) & 1 & 1 & 1 & 1 & 0 & 4 \\
\hline
\end{tabular}

The table represents an independent assessment of methodological quality of all studies included in the meta-analysis.

invasive colorectal surgery is the current standard of surgical care. The laparoscopic technique improves patient outcomes and reduces cost-effectiveness $(28,29)$. Laparoscopic colorectal procedures have been shown to enhance the return of bowel function (30).

An ultrasound-guided TAP block functions by blocking the intercostal nerve running from the spinal nerve root to result in analgesia (7). TAP block has been consistently reported to result in opioid requirements. Thus, previous studies reported up to a $70 \%$ reduction in morphine consumption after colorectal surgery in patients with TAP block using $20 \mathrm{ml}$ of $0.375 \%$ levobupivacaine (7). In another study, TAP block using $0.75 \%$ ropivacaine significantly decreased postoperative morphine consumption during $48 \mathrm{~h}$ following surgery and prolonged the time to the first analgesic request after abdominal hysterectomy (27). The early postoperative period in major surgeries is a critically important period that can be associated with complications such as respiratory depression, myocardial infarction, and hypotension. Adequate postoperative pain management and reduction in opioid consumption can reduce these complications, especially in elderly morbid patients.

Well-controlled postoperative pain has been associated with improvement in early mobilization, patient satisfaction, shortened hospital stay, reduced hospital costs, and overall improved outcomes, TAP block compared to patient-controlled analgesia found a significant decrease in intravenous opioid use a trend toward a shorter length of hospital stay (31). In some cases, TAP block fails to produce adequate analgesia. One explanation for that is not adequate coverage to achieve blockage of sensory dermatomes of the entire region in colorectal surgery. It has been reported in most of the cadaveric studies that ultrasoundguided TAP block covers T10-L1, the region localized below the umbilicus (11). Therefore, TAP can be effectively used in retropubic radical prostatectomy, hernia repair, total abdominal hysterectomy, exploratory laparotomy, and cesarean delivery (12-14). Previous studies showed that the trocar insertion sites localized above the umbilicus in the upper quadrants (T8-9 dermatome) are not covered by the TAP block $(32,33)$.
Therefore, localization of trocar insertion sites in an area that is partially covered or not covered by the TAP block could result in negative results. Since there are no major nerve bundles and the innervation is indistinct in the block region, the successful implementation of TAP block depends on the volume and spread of the local anesthetic solution within the anatomical plane. Ultrasound-guided TAP block is a relatively safe procedure, and previous studies have not found serious complications associated with this procedure $(8,12,16,34,35)$.

The ultrasound guidance improves visualization of the layers of the abdominal wall and allows safe needle placement and anesthetic injection in the correct plane.

\section{LIMITATIONS}

The main limitations of this meta-analysis are the inclusion of single centered studies and relatively small sample sizes. Since the studies had strict inclusion and exclusion criteria, they might not be representative of real-world evidence as well as patients in other countries or even other medical centers. Another possible limitation is that medical and research staff (anesthesiologists, surgeons, investigators) and patients were not blinded, therefore, these factors could also add a bias. There was also the heterogeneity among these studies in terms of timing of TAP block (preoperative vs. postoperative), reporting format of the variables, the timing of the assessment of pain severity, local anesthetics, and their volumes and concentrations, singleshot vs. continuous administration of local anesthetics, different technical modifications of TAP block.

\section{CONCLUSIONS}

This meta-analysis showed that opioid requirement within $24 \mathrm{~h}$ after surgery as well as pain intensity at rest within $24 \mathrm{~h}$ after laparoscopic and combined (laparoscopic and open) types of surgeries were significantly lower in the TAP block groups compared to "no block" groups. The intensity of pain 
during coughing within 24 hours after laparoscopic surgery was significantly lower in the TAP block groups compared to the groups without block. However, there were no statistically significant differences between the TAP block and "no block" groups in overall (i.e., within and after $24 \mathrm{~h}$ ) postoperative opioid consumption and length of hospital stay after laparoscopic surgery, as well as in postoperative nausea and vomiting after laparoscopic and combined surgeries. Since a limited number of publications and limited quality of evidence is currently available, more high-quality randomized controlled trials are required.

\section{DATA AVAILABILITY STATEMENT}

The original contributions presented in the study are included in the article/supplementary material, further inquiries can be directed to the corresponding author/s.

\section{REFERENCES}

1. Liu S. Anesthesia and analgesia for colon surgery. Region Anesth Pain M. (2004) 29:52-7. doi: 10.1016/j.rapm.2003.10.019

2. Bonnet F, Marret E. Influence of anaesthetic and analgesic techniques on outcome after surgery. Brit J Anaesth. (2005) 95:52-8. doi: 10.1093/bja/aei038

3. Kehlet H, Rung G, Callesen T. Postoperative opioid analgesia: time for a reconsideration? J Clin Anesth. (1996) 8:4415. doi: 10.1016/0952-8180(96)00131-6

4. Cali R, Meade P, Swanson M, Freeman C. Effect of morphine and incision length on bowel function after colectomy. Dis Colon Rectum. (2000) 43:1638. doi: 10.1007/BF02236975

5. Lassen K, Hannemann P, Ljungqvist O, Fearon K, Dejong C, von Meyenfeldt $\mathrm{M}$, et al. Patterns in current perioperative practice: survey of colorectal surgeons in five northern European countries. BMJ. (2005) 330:14201. doi: 10.1136/bmj.38478.568067.AE

6. Königsrainer I, Bredanger S, Drewel-Frohnmeyer R, Vonthein R, Krueger W, Königsrainer A, et al. Audit of motor weakness and premature catheter dislodgement after epidural analgesia in major abdominal surgery. Anaesthesia. (2009) 64:27-31. doi: 10.1111/j.1365-2044.2008.0 5655.x

7. McDonnell J, O’Donnell B, Curley G, Heffernan A, Power C, Laffey J. The analgesic efficacy of transversus abdominis plane block after abdominal surgery: a prospective randomized controlled trial. Anesth Analg. (2007) 104:193-7. doi: 10.1213/01.ane.0000250223.4 9963.0f

8. O'Donnell B. The transversus abdominis plane (TAP) block in open retropubic prostatectomy. Region Anesth Pain M. (2006) 31:91. doi: 10.1097/00115550-200601000-00023

9. MCDonnell J, Curley G, Carney J, Benton A, Costello J, Maharaj C, et al. The analgesic efficacy of transversus abdominis plane block after cesarean delivery: a randomized controlled trial. Obstet Anesth Dig. (2008) 28:1812. doi: 10.1097/01.aoa.0000326425.48701.14

10. Carney J, McDonnell J, Ochana A, Bhinder R, Laffey J. The transversus abdominis plane block provides effective postoperative analgesia in patients undergoing total abdominal hysterectomy. Anesth Analg. (2008) 107:205660. doi: 10.1213/ane.0b013e3181871313

11. Mukhtar K, Singh S. Transversus abdominis plane block for laparoscopic surgery. Brit J Anaesth. (2009) 102:143-4. doi: 10.1093/bja/ aen338

12. Favuzza J, Delaney C. Outcomes of discharge after elective laparoscopic colorectal surgery with transversus abdominis plane blocks and enhanced recovery pathway. J Am Coll Surg. (2013) 217:503-6. doi: 10.1016/j.jamcollsurg.2013.03.030

13. Page M, Moher D, Bossuyt P, Boutron I, Hoffmann T, Mulrow C, et al. PRISMA 2020 explanation and elaboration: updated

\section{AUTHOR CONTRIBUTIONS}

DV conceived the idea for this paper, wrote the protocol, conducted the literature review, and contributed to writing. MA extracted the data and edited the manuscript. YA conducted a statistical analysis and contributed to writing and editing. All authors contributed to the article and approved the submitted version.

\section{FUNDING}

This meta-analysis was supported by the Nazarbayev University Faculty Development Competitive Research Grant 2021-2023. Funder project reference: 021220FD2851. guidance and exemplars for reporting systematic reviews. BMJ. (2021) 372:n160. doi: 10.1136/bmj.n160

14. Luo D, Wan X, Liu J, Tong T. Optimally estimating the sample mean from the sample size, median, mid-range, and/or mid-quartile range. Stat Methods Med Res. (2016) 27:1785-805. doi: 10.1177/0962280216669183

15. Wan X, Wang W, Liu J, Tong T. Estimating the sample mean and standard deviation from the sample size, median, range and/or interquartile range. BMC Med Res Methodol. (2014) 14:1-3. doi: 10.1186/1471-2288-14-135

16. Knotkova H, Fine P, Portenoy R. Opioid rotation: the science and the limitations of the equianalgesic dose table. J Pain Symptom Manag. (2009) 38:426-39. doi: 10.1016/j.jpainsymman.2009.06.001

17. Mercadante S, Caraceni A. Conversion ratios for opioid switching in the treatment of cancer pain: a systematic review. Palliat Med. (2011) 25:50415. doi: $10.1177 / 0269216311406577$

18. Santonocito C, Noto A, Crimi C, Sanfilippo F. Remifentanilinduced postoperative hyperalgesia: current perspectives on mechanisms and therapeutic strategies. Local and Reg Anesth. (2018) 11:15-23. doi: 10.2147/LRA.S143618

19. Jadad A, Moore R, Carroll D, Jenkinson C, Reynolds D, Gavaghan D, et al. Assessing the quality of reports of randomized clinical trials: is blinding necessary? Control Clin Trials. (1996) 17:1-12. doi: 10.1016/0197-2456(95)00134-4

20. Haruethaivijitchock P, Ng J, Taksavanitcha G, Theerawatanawong J, Rattananupong T, Lohsoonthorn V, et al. Postoperative analgesic efficacy of modified continuous transversus abdominis plane block in laparoscopic colorectal surgery: a triple-blind randomized controlled trial. Tech Coloproctol. (2020) 24:1179-87. doi: 10.1007/s10151-020-02311-9

21. Xu Y, Sun X, Jiang H, Yin Y, Weng M, Sun Z, et al. Randomized clinical trial of continuous transversus abdominis plane block, epidural or patient-controlled analgesia for patients undergoing laparoscopic colorectal cancer surgery. $\mathrm{Br} \mathrm{J}$ Surg. (2020) 107:e133-41. doi: 10.1002/bjs.11403

22. Damadi A, Lax E, Smithson L, Pearlman R. Comparison of therapeutic benefit of bupivacaine HCL transversus abdominis plane (TAP) block as part of an enhanced recovery pathway versus traditional oral and intravenous pain control after minimally invasive colorectal surgery: a prospective, randomized, double-blind trial. Am Surg. (2019) 85:13638. doi: $10.1177 / 000313481908501230$

23. Oh T, Yim J, Kim J, Eom W, Lee S, Park S, et al. Effects of preoperative ultrasound-guided transversus abdominis plane block on pain after laparoscopic surgery for colorectal cancer: a double-blind randomized controlled trial. Surg Endosc. (2016) 31:127-34. doi: 10.1007/s00464-016-4941-7

24. Smith S, Draganic B, Pockney P, Holz P, Holmes R, Mcmanus B, et al. Transversus abdominis plane blockade in laparoscopic colorectal surgery: a double-blind randomized clinical trial. Int J Colorectal Dis. (2015) 30:123745. doi: 10.1007/s00384-015-2286-7 
25. Keller D, Ermlich B, Schiltz N, Champagne B, Reynolds H, Stein S, et al. The effect of transversus abdominis plane blocks on postoperative pain in laparoscopic colorectal surgery. Dis Colon Rectum. (2014) 57:12907. doi: 10.1097/DCR.0000000000000211

26. Walter C, Maxwell-Armstrong C, Pinkney T, Conaghan P, Bedforth N, Gornall $\mathrm{C}$, et al. A randomised controlled trial of the efficacy of ultrasound-guided transversus abdominis plane (TAP) block in laparoscopic colorectal surgery. Surg Endosc. (2013) 27:2366-72. doi: 10.1007/s00464-013-2791-0

27. Bharti N, Kumar P, Bala I, Gupta V. The efficacy of a novel approach to transversus abdominis plane block for postoperative analgesia after colorectal surgery. Anesth Analg. (2011) 112:15048. doi: 10.1213/ANE.0b013e3182159bf8

28. Keller D, Delaney C, Hashemi L, Haas E, A. national evaluation of clinical and economic outcomes in open versus laparoscopic colorectal surgery. Surg Endosc. (2015) 30:4220-8. doi: 10.1007/s00464-015-4732-6

29. Schwenk W, Haase O, Neudecker J, Müller J. Short term benefits for laparoscopic colorectal resection. Cochrane Database Syst Rev. (2005) 67. doi: 10.1002/14651858.CD003145.pub2

30. Delaney C, Brady K, Woconish D, Parmar S, Champagne B. Towards optimizing perioperative colorectal care: outcomes for 1,000 consecutive laparoscopic colon procedures using enhanced recovery pathways. Am J Surg. (2012) 203:353-6. doi: 10.1016/j.amjsurg.2011. 09.017

31. Conaghan P, Maxwell-Armstrong C, Bedforth N, Gornall C, Baxendale B, Hong L, et al. Efficacy of transversus abdominis plane blocks in laparoscopic colorectal resections. Surg Endosc. (2010) 24:2480-4. doi: 10.1007/s00464-010-0989-y

32. Børglum J, Jensen K, Christensen A, Hoegberg L, Johansen S, Lönnqvist P, et al. Distribution patterns, dermatomal anesthesia, and ropivacaine serum concentrations after bilateral dual transversus abdominis plane block. Reg Anesth Pain Med. (2012) 37:294-301. doi: 10.1097/AAP.0b013e31824c20a9

33. Tran T, Ivanusic J, Hebbard P, Barrington M. Determination of spread of injectate after ultrasound-guided transversus abdominis plane block: a cadaveric study. Br J Anaesth. (2009) 102:123-7. doi: 10.1093/bja/aen344

34. Rafi A. Abdominal field block: a new approach via the lumbar triangle. Anaesthesia. (2001) 56:1024-6. doi: 10.1111/j.1365-2044.2001.2279-40.x

35. Kuppuvelumani P, Jaradi H, Delilkan A. Abdominal nerve blockade for postoperative analgesia after caesarean section. Asia Oceania J Obstet Gynaecol. (2010) 19:165-9. doi: 10.1111/j.1447-0756.1993.tb00368.x

Conflict of Interest: The authors declare that the research was conducted in the absence of any commercial or financial relationships that could be construed as a potential conflict of interest.

Publisher's Note: All claims expressed in this article are solely those of the authors and do not necessarily represent those of their affiliated organizations, or those of the publisher, the editors and the reviewers. Any product that may be evaluated in this article, or claim that may be made by its manufacturer, is not guaranteed or endorsed by the publisher.

Copyright (C) 2022 Viderman, Aubakirova and Abdildin. This is an open-access article distributed under the terms of the Creative Commons Attribution License (CC BY). The use, distribution or reproduction in other forums is permitted, provided the original author(s) and the copyright owner(s) are credited and that the original publication in this journal is cited, in accordance with accepted academic practice. No use, distribution or reproduction is permitted which does not comply with these terms. 